\title{
¿LA CULTURA COMO RECURSO? ESTUDIOS DE CASO EN DOS PROYECTOS DE ORQUESTAS JUVENILES CON OBJETIVOS DE INCLUSIÓN SOCIAL EN LA CIUDAD DE BUENOS AIRES, ARGENTINA
}

GABRIELA WALD*

\begin{abstract}
RESUMEN
El presente artículo analiza las potencialidades y límites de dos proyectos de Orquestas Juveniles en barrios populares para influir en distintos aspectos de la vida de sus destinatarios: en sus representaciones, en algunas prácticas, en cuestiones identitarias o de subjetividad, y en la formulación de sus proyectos biográficos. Distanciándose de las dos posiciones habituales a partir de los cuales los mismos han sido interpretados - la celebración integradora y la crítica por reproducir espacios de dominación- el estudio muestra que solo determinados jóvenes de sectores populares pueden permanecer en estos espacios. No obstante, cuando esto ocurre, pueden darse procesos de transformación.
\end{abstract}

PALABRAS CLAVE: JÓVENES, POLÍTICAS SOCIALES, POLÍTICAS CULTURALES

* Doctora en Ciencias Sociales. Investigadora Adjunta del Consejo Nacional de Investigaciones Científicas y Tecnológicas, Argentina. Sede de trabajo: Instituto de Investigaciones Gino Germani, Facultad de Ciencias Sociales, Universidad de Buenos Aires. MA en Educación, Promoción de la Salud y Desarrollo Internacional (Institute of Education, University of London). Consultora en cuestiones de juventud, cultura y promoción de la salud. E-Mail: gawald@gmail.com. 


\title{
A CULTURA COMO RECURSO? \\ ESTUDOS DE CASO EM DOIS PROJETOS DE ORQUESTRAS JUVENIS COM METAS DE INCLUSÃO SOCIAL NA CIDADE DE BUENOS AIRES, ARGENTINA
}

\begin{abstract}
RESUMO
O presente artigo analisa as potencialidades e limites de dois Projetos de Orquestras Juvenis em bairros populares para influir nos diferentes aspectos da vida de seus destinatários: em suas representações, em algumas práticas, em questões de identidade ou de subjetividade e na formulação de seus projetos biográficos. Afastando-se das duas posições habituais a partir dos quais eles foram interpretados - a celebração integradora e a crítica por reproduzir espaços de dominação - o estudo mostra que apenas determinados jovens dos setores populares podem permanecer nestes espaços. No entanto, quando isso acontecer, podem haver processos de transformação.
\end{abstract}

PALAVRAS CHAVE: JOVENS, POLÍTICAS SOCIAIS, COLÍTICAS CULTURAIS

\section{IS THE CULTURE USED AS A RESOURCE? CASE STUDIES ON TWO PROJECTS OF YOUTH ORCHESTRAS WITH SOCIAL INCLUSION GOALS IN THE CITY OF BUENOS AIRES, ARGENTINA}

\begin{abstract}
This article analyzes the potentials and limitations of two projects of youth orchestras in working-class neighborhoods to influence different aspects of the young participants lives: in their representations, some of their practices, their identities and subjectivities construction, and in the formulation of their biographical projects. Distancing from the two most common positions used to interpret these programs - those that celebrate them as «social integration» interventions and those that criticize them for reproducing practices of domination - the research shows that only some young people of these neighborhoods can participate and stay in this kind of projects. Nevertheless, when this occurs, processes of transformation can take place.
\end{abstract}




\section{LA EXTENSIÓN DEL FENÓMENO DE ORQUESTAS JUVENILES EN AMÉRICA LATINA}

DURANTE LOS ÚLTIMOS VEINTE años del siglo XX, y tomando como modelo el Sistema Nacional de Orquestas Juveniles e Infantiles de Venezuela, se propagaron en América Latina proyectos de orquestas infantiles y juveniles que se propusieron acercar la experiencia orquestal y la música académica ${ }^{1}$ a sectores de la población que, salvo excepciones puntuales, no habían tenido acceso a ellas.

Diversos organismos de cooperación y crédito internacional abonaron este proceso: la Organización de Estados Americanos (OEA) ha apoyado la formación de orquestas infantiles y juveniles en más de veinte países del continente, mientras que la UNESCO proclamó en 1995 la formación y consolidación de un Sistema Mundial de Orquestas y Coros Juveniles e Infantiles, otorgando de ese modo relevancia y prioridad mundial a proyectos de estas características.

En Argentina, las primeras orquestas infanto-juveniles para la formación musical de niños, niñas, adolescentes y jóvenes se crearon en el año 1998 en Chascomús, Bariloche y en la Ciudad de Buenos Aires; sin apoyo externo y a partir de acciones aisladas de entidades gubernamentales locales, organizaciones de la sociedad civil y/o de músicos independientes; todos inspirados en el modelo venezolano. A diecisiete años de esas experiencias el fenómeno se ha extendido y diversificado, y existen en nuestro país no menos de 80 orquestas infantiles y juveniles que ofrecen formación de modo gratuito, que involucran a más de 6.500 niños, niñas y jóvenes en al menos 15 provincias. $^{2}$

1 Llamo música académica a la música que deriva de las tradiciones del arte europeo y de la música de concierto, y que abarca un amplio período que va desde el año 1000 hasta el presente. Si bien coloquialmente se conoce a esta tradición musical como «música clásica», denominarla de este modo resultaría impreciso ya que existe un período de la música académica que va desde 1750 a 1820 — cuyos principales exponentes son Haydn, Mozart y el primer Beethoven-que lleva el nombre de período clásico.

2 Estos datos surgen de un relevamiento propio a partir de fuentes secundarias, Internet, intercambios por e-mail y conversaciones telefónicas con personas vinculadas a orquestas en Argentina. A pesar de existir un programa de la Secretaría de Cultura de la Nación que nuclea y gestiona orquestas juveniles en todo el país, no existen datos sobre la cantidad de orquestas en funcionamiento ni la cantidad de participantes que las 
La extensión de programas de enseñanza artística en barrios populares con fines de integración social en diferentes partes del mundo debe leerse enmarcada en dos fenómenos sociales ocurridos durante las últimas décadas. El primero de ello es la centralidad que adquirió la focalización de la política social en los Estados otrora benefactores, focalización que emergió como resultado de profundos cambios en los modelos de acumulación en gran parte del mundo occidental (Repetto y Andrenacci, 2006). El segundo es la emergencia de un nuevo modo de concebir y gestionar la cultura, la cual se transforma en una herramienta o recurso mediante la cual se pueden (y deben) resolver problemas tanto económicos como sociales (Yúdice, 2002).

Durante el proceso de investigación que dio lugar a este artículo - extenso y discutido pues fue parte de mi tesis doctoral — he podido comprobar que existen dos posiciones, lo suficientemente opuestas como para sospechar de ambas, a partir de las cuales suelen interpretarse los proyectos de orquestas infantiles y juveniles que se proponen extender la práctica orquestal a sectores sociales habitualmente alejados de ella.

En un extremo podría ubicar las posiciones que he dado en llamar celebratorias de este tipo de orquestas, que destacan las bondades y beneficios de participar en ellas. Las mismas son movilizadas en su mayoría por comunicadores sociales, por organismos internacionales (OEA, UNESCO, UNICEF, UNDP, el BID), gobiernos nacionales y locales, por cuadros técnicos y políticos — gubernamentales y del tercer sector-, por promotores y gestores de orquestas y proyectos artísticos afines, y también por algunos académicos de la educación, la educación a través del arte, la psicología de la música, la musicología, las políticas infantiles y juveniles, la economía, y lo poco que se ha escrito sobre este tema desde la antropología y la sociología. Estas posiciones han circulado ampliamente en los medios masivos de comunicación - en voces tanto de periodistas como de gestores de políticasen documentos que sistematizan y evalúan proyectos de orquestas y otras intervenciones de educación artística similares, en documentos internos de las mismas orquestas y en resultados de investigaciones académicas de los campos disciplinares ya citados.

Sosteniendo una posición opuesta estarían las voces críticas, herederas de los estudios culturales ingleses y franceses, de los estu-

mismas nuclean. Los datos que se presentan aquí son, por lo tanto, aproximados. 
dios sobre culturas populares, de la pedagogía crítica y la educación popular, de los análisis de políticas culturales en América latina en general, y de políticas culturales con sectores populares en particular. A diferencia de la gran circulación de la que han gozado las posiciones celebratorias, no puede decirse lo mismo de las críticas: durante la extensa revisión bibliográfica realizada no he logrado encontrar ninguna publicación que analice críticamente un proyecto de orquestas infanto/juveniles en ningún país. Sin embargo, existen decenas de textos y autores cuyas reflexiones teórico/analíticas aplicadas a mi objeto de estudio obligarían a contextualizar los proyectos de orquestas en el marco de estructuras de dominación y relaciones desiguales de poder; y en la mayoría de los casos, a desestimarlos como política pública por reproducir dichas estructuras de manera acrítica.

\section{a) Las posiciones celebratorias: posturas claras sobre los beneficios de las orqueras}

Los medios de comunicación, adalides de la solidaridad humanitaria y civilizatoria, aparecen siempre entusiasmados con la idea de extender la formación de orquestas entre jóvenes que provienen, en su mayoría, de sectores populares. Se esfuerzan por describir minuciosamente la carencia de los barrios y hogares de los cuales los jóvenes provienen para luego contrastarlas con las virtudes adquiridas a través de la práctica orquestal. $^{3}$

Para la mayoría de los medios, entonces, los proyectos de orquestas permitirían tanto «ganarle a la pobreza con la música» (Clarín, 2005) o «romper el círculo de la pobreza» (La Nación, 2004) como «fortalecer la autoestima» (La Nación, 2005), «encontrar el entrena-

3 Para muestra basta un fragmento: «Después de un rato, los Juárez bajan y tocan en la calle. Siete chicos corren a sentarse en los escalones de un quiosco. Cinco madres se juntan, cadera con cadera, en el alféizar de una ventana. Desde los balcones, se asoman las vecinas con los pulóveres arremangados y las manos espumosas de jabón. Nadie nunca ha visto eso en el barrio... La música sube como un rayo, después gotea sobre las casas de cuartos pequeños, sobre la ropa colgada, sobre los trabajos y la falta de trabajo y las fatigas. Nada es mejor, pero por un rato parece, porque los Juárez tocan como si el barrio fuera el mundo y esa calle tranquila la cubierta de un buque suntuoso que les lame los zapatos. Desde el balcón de la casita del Fonavi el perro aúlla. La banda ríe. La banda sigue tocando» (La Nación, 2005a). 
miento para una vida mejor» (La Nación Revista, 2005) y devolverles a los jóvenes la posibilidad de «creer en ellos mismos» (Crítica de la Argentina, 2008). Es decir, el proyecto estaría impactando tanto en variables estructurales como en aspectos del desarrollo personal de los jóvenes. De este modo, la práctica orquestal es concebida como una herramienta esencial tanto para educar al pueblo en prácticas y valores legítimos como para intervenir sobre un actor social - el joven-que es representado y tratado por la mayoría del mundo adulto como problema (Chaves, 2005). ${ }^{4}$

En línea con algunas de estas ideas - aunque con menores dosis de etnocentrismo, romanticismo y pensamiento mágico-, las orquestas son consideradas por quienes las promueven y gestionan como proyectos de «integración social para jóvenes en situación de vulnerabilidad», «promotoras de vínculos y capacidades para la vida», cuyos resultados «se reflejan en importantes modificaciones en la conducta de los participantes» (GCBA, 2009a y 2009b). Los gestores de estos y otros proyectos artísticos, así como diversos cuadros técnicos y políticos - gubernamentales y del tercer sector - comparten la visión sobre los beneficios de participar en estos proyectos. Hacen hincapié en las posibilidades de «inclusión social» o «integración» de niños/as y jóvenes de zonas «históricamente postergadas» que generan estas iniciativas, a partir del fomento tanto de la «capacidad creadora» como del «desarrollo sociocultural» y el «derecho a la equidad» de los participantes. En general, los programas identifican «beneficios secundarios» que esperan producir en sus destinatarios que van desde «modificaciones en la conducta», «en la autoestima» o mejoras en el «rendimiento escolar» hasta la posibilidad de «pensar nuevas alternativas de vida y de creación individual» (GCBA, 2009a; GCBA, 2009b; Atela, 2005; Joly, Santiago, Joly, Penteado, 2002).

Montados sobre un discurso tan extendido como ambiguo en sus sentidos y alcances como es el de la inclusión social, ${ }^{5}$ la postura de

4 Mariana Chaves (2005) señala que en nuestras sociedades se han naturalizado ciertas cualidades como propias de los jóvenes que justificarían la intervención sobre ellos. Los medios reproducen, en palabras de la autora, el «discurso del pánico moral», según el cual la sociedad se acerca a ellos «a través del miedo, de la idea del joven como desviado y peligroso» (p.23). Según este discurso, a los jóvenes hay que atenderlos, cuidarlos, guiarlos, controlarlos, etcétera.

5 El concepto de inclusión social, así como su antónimo, el de exclusión, han sido utilizados por una gran variedad y extensión de actores sociales 
políticos y técnicos - en especial de aquellos que gestionan proyectos similares - se diferencia de la celebración mediática porque no parten de una mirada caritativa sino de reconocer a los jóvenes y sus familias la capacidad de agencia, confiando en que la educación artística proveerá aquello que las políticas neoliberales y la retirada del Estado han quitado.

Las concepciones celebratorias han sido también adoptadas como se dijo por organismos internacionales — la OEA y UNESCO-, pero también el PNUD (1998), el Banco Interamericano de Desarrollo -quien ha desembolsado cuantiosas sumas para financiar proyectos de orquestas y coros juveniles- (De Couve y Dal Pino, 2007), y UNICEF, que considera que estos proyectos aportan herramientas para una plena ciudadanía (UNICEF, Secretaría de Cultura de la Nación y Fundación Arcor, 2008).

Finalmente, la celebración también puede hallarse en estudios realizados en su mayoría por estudiantes o investigadores de universidades y centros de investigación de distintas disciplinas, mayormente en América latina. Algunos de ellos afirman que las orquestas permiten a los participantes «sentirse parte de una sociedad que antes los marginaba» (Fernández Calvo, 2003:10); que participar en las orquestas mejora el rendimiento escolar de los jóvenes (Egaña del Sol, 2007), que el hacer musical es una experiencia que trasciende la ocupación del tiempo ocioso y «repercute en la organización de las subjetividades de los jóvenes... construyendo sentidos» (Hikiji, 2006:22) o que la performance musical genera transformaciones a nivel emocional, social y cultural como consecuencia de participar en actividades, que ofrecen «un momento lúdico, de placer... que instruye, incentiva y valoriza la libertad de expresión y reflexión» (Chevitarese, 2007:77). Incluso un trabajo en Chile que arroja algunos sentidos de la práctica orquestal similares a los que arrojó la investigación que dio lugar a este artículo (Velasco San Martín, 2009), plantea una postura en línea con la celebración de estas iniciativas en tanto promotoras de desarrollo local.

para referirse a problemas vinculados a la pobreza y la marginalidad (y a sus posibles soluciones). No obstante, los sentidos otorgados a ambos conceptos no sólo no son unívocos sino que aún continúan en discusión (Ver Wald, 2012:282-300) 


\section{b) Las posiciones críticas: fragmentarias, dispersas, insinuadas}

En contraposición a la gran cantidad de discursos y miradas celebratorias sobre los programas de orquestas juveniles en América latina, es posible ubicar un abanico de posiciones críticas. Las mismas no han sido plasmadas en textos ni documentos específicos que analicen proyectos de orquestas sino que pueden inferirse de trabajos y reflexiones teórico-analíticas desarrolladas en los campos de los estudios culturales, las culturas populares, las políticas culturales con sectores populares y la pedagogía crítica - campos que han centrado sus análisis en las dimensiones políticas de las prácticas culturales y las intervenciones educativas-. Durante mi trabajo de investigación, las posiciones críticas han sido sostenidas por colegas y docentes que trabajan en el marco de estos campos disciplinares, muchos de los cuales consideran que las orquestas juveniles en barrios populares son «como misiones jesuíticas que vienen a evangelizar al pueblo en valores cultos» $\mathrm{O}$ «intervenciones que reproducen esquemas de dominación». Veremos entonces qué marcos teóricos podrían habilitar interpretaciones de este tipo.

Los estudios culturales británicos ${ }^{6}$ fueron pioneros en interrogar el modo en que las relaciones de dominación se internalizan en las prácticas cotidianas, en principio haciendo foco en la experiencia de los sectores populares (Turner, 1996). Ligados al marxismo crítico europeo e influenciados por el estructuralismo, la intención de estos estudiosos era revelar las relaciones de poder constitutivas de las prácticas de la vida cotidiana. Y se valieron para esto del concepto gramsciano de hegemonía.

Para Rymond Williams (2000:64), las artes son «formas de control y especialización de una clase sobre una práctica social general», de lo cual podríamos inferir que para él las orquestas sinfónicas formarían parte de estas prácticas apropiadas de manera desigual por diferentes clases sociales, y que en los programas orquestales esta práctica estaría siendo transmitida de acuerdo a concepciones domi-

6 Los trabajos fundacionales de este campo de estudio son «The Uses of Literacy», de Richard Hoggart y «Culture and Society» de Rymond Williams, ambos escritos en 1958. El Centro de Estudios Culturales Contemporáneos de Birmingham fue el epicentro desde el cual este campo disciplinar se construyó, y sus principales exponentes han sido, además de los arriba citados, Edward Palmer Thompson, Stuart Hall, John Clarke y Paul Willis. 
nantes. Por lo tanto, sería una forma de dominación y control de una clase por sobre otra.

En línea con esta idea, los franceses Grignon y Passeron (1991) criticarían los programas de orquestas juveniles en barrios populares ya que, tanto la orquesta sinfónica como los argumentos que justifican la creación de programas de orquestas juveniles serían, desde su perspectiva, dominocéntricos y dominomórficos. ${ }^{7}$

$\mathrm{Si}$, como dijo el creador del sistema de orquestas venezolano, la música solo puede ser «un instrumento de cambio social» si es alta música (Abreu, 2001 -al recibir el premio Nobel alternativo de la paz), es clara la desvalorización de los universos simbólicos populares y la confianza en la alta cultura como redentora de las carencias y males del pueblo en general - y de los jóvenes del pueblo en particular - que tiene este proyecto tan celebrado. Cuesta imaginar una visión más alejada del modo en que proponen concebir las culturas populares Grignon y Passeron, quienes intentan devolverles la riqueza simbólica que, según ellos, las interpretaciones sociológicas legitimistas les han quitado. ${ }^{8}$

La corriente Freiriana de educación popular también criticaría las modalidades de intervención y las estrategias pedagógicas de las experiencias orquestales que se han expandido en América Latina. Para estos autores, el objetivo de crear una «democracia crítica» (Giroux, 1988:62) que apunte a fortalecer la libertad individual, la justicia so-

7 Dominocentrismo y dominoformismo son términos desarrollados en el libro «Lo culto y lo popular» (Grignon y Passeron, 1991) para referirse al etnocentrismo de clase con que algunos analistas describen los universos simbólicos populares en tanto carencia, privación y «falta de gusto»—en contraposición a una cultura legítima distinguida. Según Grignon y Passeron, gran parte de los sociólogos abordan las culturas populares con los conceptos que utilizan para analizar las formas simbólicas hegemónicas y esto implicaría dominocentrismo (el punto de referencia son las prácticas simbólicas dominantes) y dominoformismo (se analizan las formas simbólicas populares a imagen y semejanza de las dominantes).

8 Grignon y Passeron (1991) arremeten contra dos posturas en relación al pueblo que creen deben ser superadas: el populismo y el legitimismo. Por populismo entienden la conversión de los analistas a las causas del pueblo afirmando la superioridad de sus costumbres y competencias, y por legitimismo el pensar que las clases altas son siempre dominantes y su cultura legítima en contraposición a las prácticas culturales populares, siempre devaluadas. 
cial y por sobre todo, a generar el cambio social, no estaría asegurado en estos programas, dado que no hay un trabajo de concientización del lugar que los jóvenes ocupan en el espacio social (Freire, 2005). Por el contrario, en lugar de desarrollar ideas y conceptos alternativos a los discursos dominantes, estos jóvenes reproducirían aquello que sus docentes de música les enseñan, artefactos de una cultura impuesta. Estos autores criticarían también la dinámica pedagógica por ser el docente el único emisor de un saber dado que no se elabora de manera participativa (Apple, 1996; Kaplun, 2004).

Por su parte, diversos académicos de los campos de la comunicación y la sociología de la cultura en América latina y Argentina han trabajado problemáticas ligadas a las políticas culturales, en particular con sectores populares (García Canclini, 1987; Landi, 1987; Rubinich, 1993; Winocur, 1996; Del Cueto, 2006). Si aplicáramos sus reflexiones al análisis de los proyectos de orquestas juveniles en barrios populares la mayoría de estos autores reconocería el componente democratizador de este tipo de proyectos (mejorar el acceso de los jóvenes de sectores populares a un bien cultural distribuido de manera desigual), pero lo criticarían por ser extensionista y difusionista. Es decir, por privilegiar la alta cultura por sobre las culturas populares y por reproducir entre los jóvenes de estos sectores ideas, concepciones y sentidos asociados a grupos hegemónicos. Algunos de estos autores - retomando las ideas de la educación popular- dirían que los proyectos de orquestas no debieran ser ideados y gestionados por «expertos» y que los universos simbólicos de los participantes también debieran integrarse en el diseño de políticas culturales. Así, dirían que si bien democratizar el acceso a la producción de bienes de la alta cultura es positivo, faltaría introducir el trabajo con los productos y sistemas de valores de los sectores populares.

\section{c) Un enfoque inductivo: hacia un análisis de las orquestas desde abajo}

Hemos visto hasta aquí la existencia de dos formas casi opuestas de interpretar las orquestas juveniles en tanto políticas públicas. De las posiciones celebratorias podemos decir que parten de la fe en el arte como herramienta para la formación y el desarrollo del ser humano en sus aspectos individuales y colectivos, y en la creatividad como facilitadora de soluciones para la vida cotidiana. Hacen propio el concepto de exclusión social y su antónimo, el de inclusión o integración so- 
cial $^{9}$, sin detenerse en las causas de dicha exclusión, implicando una perspectiva más centrada en los aspectos individuales de las soluciones posibles. Asimismo, subyace aquí el supuesto moral de que es preciso hacer del otro alguien semejante a uno, pues la comunidad de similares implica menores dosis de tensión.

Las posiciones críticas, por su parte, plantean la correspondencia entre una práctica artística o cultural y una clase o sector social que la ha creado y a quien, de alguna manera, le pertenece. El difundir una práctica de la alta cultura entre sectores populares estaría implicando, antes que nada, relaciones de hegemonía/subalternidad. Para muchos de los colegas que sostienen este tipo de interpretaciones la permanencia de jóvenes de sectores populares en proyectos de orquestas sinfónicas solo se explica por ser éstas parte de la cultura legítima ${ }^{10}$ que las comunidades intentan apropiar para sí. Y la participación de estos jóvenes sería uno más de los modos de dominación del pueblo. ${ }^{11} \mathrm{El}$ supuesto moral de estas posiciones implica la necesidad de hacer que el pueblo, por un lado, resista las imposiciones de la cultura hegemónica, y por el otro, pueda crear formas propias de expresión y estetización.

La existencia de estos dos polos de interpretación sorprende por su contraste y en algunos casos por su radicalidad ¿Qué lugar ocupan las culturas populares para quienes sostienen una posición celebratoria? ¿En qué se basan para otorgar un estatus diferente a la música académica por sobre otros géneros musicales? ¿Por qué están tan convencidos de que el arte es bueno para todos? ¿Acaso el arte no es una práctica social situada y por lo tanto, atravesada por relaciones de poder? Los programas y proyectos sociales ¿no implican intercambios desiguales? Y entonces ¿es posible afirmar que el arte es una herramienta para la transformación social aún en el marco de estos programas? Las posiciones críticas, por su parte, parecieran no tomar en cuenta que las prácticas culturales legítimas no necesariamente son apropiadas por los sectores populares del modo en que lo hacen los

9 Estos conceptos, aunque parecen transparentes, adquieren diferentes sentidos según quién los utilice y con qué marcos teóricos se combinen. (Ver Wald, 2012:282-300)

10 Como hemos comentado más atrás en este capítulo, por cultura legítima se entiende a la alta cultura.

11 Quisiera recalcar que en varios seminarios doctorales fui criticada por sociólogos de la cultura por proponerme analizar programas de orquestas juveniles ya que la explicación se clausuraba, según ellos, con la referencia a la cultura legítima y a la lucha por su apropiación. 
sectores hegemónicos y que, en consecuencia, una práctica artísticocultural no debiera ser entendida como autónoma o subordinada en su totalidad. ¿Acaso no pueden existir diferentes tipos de apropiaciones (o usos) de las culturas legítimas que valgan la pena ser explorados, aún en el marco de estructuras de producción simbólica hegemónicas? ¿No debiéramos cuestionar la correlación causal que tanto las posturas celebratorias como las críticas establecen entre música y consecuencias sociales (integración social por un lado, dominación por el otro)? $\mathrm{Si}$, como afirman las posiciones críticas, consumimos y producimos lo que somos capaces de consumir y producir, ¿no estamos cerrando el debate al asumir que el valor estético atribuido a una música dependerá siempre del lugar que ocupamos en la estructura social? ¿No valdría la pena analizar si una práctica artístico-expresiva puede ayudar a construir o a dar sentido a sujetos individuales o colectivos aún cuando esa práctica sea de la alta cultura ofrecida a sectores medios empobrecidos o populares?

En el presente artículo presento resultados de una investigación cualitativa realizada en el marco de dos proyectos de orquestas juveniles en dos barrios populares de la Ciudad de Buenos Aires, Argentina. Analizo estas políticas socio-culturales desde una perspectiva que se distancia tanto de las interpretaciones celebratorias como de las críticas, pues considero que ambas lecturas son generalizaciones derivadas de razonamientos deductivos que parten de supuestos teóricos, políticos y morales que deberían ser complejizados. La investigación realizada, de carácter inductivo, aporta elementos para discutir los límites y las potencialidades de las orquestas juveniles para promover cambios en distintos aspectos de la vida de sus jóvenes destinatarios: en algunas de sus representaciones, de sus prácticas, en aspectos relativos a lo que consideran su subjetividad, en cuestiones identitarias y en la formulación de horizontes de expectativas ${ }^{12}$ y proyectos biográficos.

12 El concepto Horizonte de expectativas remite a lo que cada persona espera para sí del porvenir. Alude a la esperanza, a la posibilidad, a lo deseable y a la voluntad (Kosellek, 1985). En algunos casos pueden tomar la forma de proyectos biográficos, aunque no es posible afirmar que todas las personas logran articular este tipo de relato de aquello que esperan para su propia vida. 


\section{d) Apuntes sobre objetivos, metodología y casos seleccionados}

Durante el proceso de investigación de campo se revelaron algunas cuestiones importantes para la indagación. Me propuse entonces: a) comprender los sentidos que los jóvenes y sus padres/madres u otros adultos a cargo otorgaban al paso por los proyectos de orquestas juveniles, b) analizar los modos en que se apropiaban de aquello que los proyectos les proponían; es decir, qué usos hacían de los mismos; y c) rastrear qué elementos podrían estar influyendo en estos sentidos y apropiaciones. Para esto último, indagué si existían regularidades entre los sentidos y usos de las orquestas y distintas características de los jóvenes y sus familias (posición socioeconómica, trayectorias educativa, laboral, residencial; y repertorios culturales).

Para realizar este recorrido opté por un enfoque metodológico cualitativo, interpretativo y de inspiración etnográfica, pues las dos características básicas del método etnográfico 1) la presencia sostenida del investigador en el terreno donde tienen lugar las prácticas que analiza y 2) el trabajo con los sentidos y representaciones de los actores a partir de sus perspectivas y puntos de vista (Wolcott, 2006; Guber, 2001) se revelaron centrales para abordar las preguntas problema de este estudio.

La investigación constó de dos etapas. La primera comenzó en abril del año 2010 e implicó la inserción en la que (para resguardar la confidencialidad de los datos) llamaremos la «Orquesta Juvenil A», durante un año y medio. La segunda comenzó en agosto de 2010 con la inserción en la que llamaremos la «Orquesta Juvenil B» y se extendió hasta marzo de 2012. Ambos proyectos se desarrollaban en dos barrios del sur de la Ciudad de Buenos Aires.

Los dos proyectos seleccionados resultaban a grandes rasgos similares: ofrecían clases de instrumentos, de lenguaje musical y práctica en orquesta. Asimismo, entregaban un instrumento en comodato a cada uno de los participantes para que pudieran practicar en otros momentos de la semana. La dirección artística de ambos proyectos estaba a cargo de la misma persona (un reconocido músico y ex director de uno de los conservatorios de la Ciudad de Buenos Aires) y por tal razón, los repertorios eran similares (variaba la dificultad de acuerdo a las posibilidades de interpretación de cada joven/grupo).

Ambos proyectos presentaban también algunas diferencias. En primer lugar, las orquestas estaban gestionadas por distintos sectores del Gobierno de la Ciudad (Educación una, Cultura la otra). En la 
Orquesta A, la mayor parte de los jóvenes vivía en una villa de emergencia cercana, mientras que en la Orquesta B la composición socioeconómica era más heterogénea (jóvenes provenientes de grandes conglomerados de viviendas sociales, de villas de emergencia, de barrios populares cercanos y de las zonas residenciales del barrio, estas últimas habitadas por clases medias y medio/bajas). Asimismo, en la Orquesta A los jóvenes comenzaban a participar a partir de los trece años, mientras que en la Orquesta B comenzaban de niños, entre los seis y los doce años. Una cuarta diferencia tenía que ver con el peso del componente social en relación al meramente musical: la Orquesta B se ocupaba de formar niños/as y adolescentes en habilidades expresivas, instrumentales y musicales sin indagar en aspectos de la vida privada o familiar de los participantes. La Orquesta A, por el contrario, articulaba con otros sectores del gobierno local enfatizando el peso de la intervención social del programa (el Ministerio de Trabajo otorgaba unas becas y el de Salud ofrecía información y consultorías a los jóvenes asistiendo a los ensayos cada quince días).

El abordaje metodológico de la investigación implicó la triangulación de información obtenida a lo largo de un año de observaciones (con y sin participación) en cada orquesta, 8 grupos de discusión con jóvenes, 42 entrevistas en profundidad ( 22 a jóvenes participantes, 12 a padres y/o madres y 8 a docentes $u$ otros gestores), observaciones esporádicas posteriores a las entrevistas, análisis de documentos producidos por los proyectos y lectura de notas periodísticas.

\section{SENTIDOS Y USOS DE LA PRÁCTICA ORQUESTAL}

\section{a) De la participación en un espacio valorado a la apropiación de la música y el instrumento en el proyecto biográfico}

En líneas generales, los adolescentes y jóvenes de las dos orquestas valoran positivamente la actividad: cuando se les pidió que le pusieran un puntaje al proyecto en el que participan, todos los ubicaron entre ocho y diez. El hecho de que permanezcan en esos espacios - permanencia que variaba entre dos y diez años entre quienes formaron parte de este estudio en ambas orquestas - muestra a través de las prácticas lo que han verbalizado en las distintas instancias de investigación.

Los jóvenes de ambas orquestas aprecian la actividad principalmente porque: a) brinda nuevos conocimientos, socialmente valorados (música académica, «cultura», «arte»); b) proporciona disfrute (tanto 
arriba como abajo del escenario); c) supone un lugar «distinto» de encuentro con pares del barrio (difiere de la escuela por la relación que establecen con los docentes, de la calle por ser un espacio con una propuesta educativa, de actividades de centros culturales barriales por brindar contenidos considerados «de calidad», de otras actividades para jóvenes atravesadas por la militancia partidaria por no manifestar contenidos políticos); d) permite a los jóvenes conocer nuevos ámbitos de la ciudad y actores sociales con quienes previamente no interactuaban (tocar en teatros consagrados como el Colón o el Coliseo, en espacios urbanos reconocidos como la Catedral Metropolitana o el Centro Cultural Borges, tocar con músicos de la talla de Marta Argerich, León Gieco, Javier Calamaro o con bandas de rock como la Bersuit Vergarabat; conocer gente del campo de la comunicación y la cultura como investigadores, cineastas, productores y conductores de TV). Todo esto es vivenciado como enriquecedor de la propia experiencia, imposible de alcanzar sin la intervención de los proyectos.

Los padres entrevistados comparten estas apreciaciones, y agregan que las orquestas constituyen un lugar «seguro» para sus hijos, donde quienes participan son otros jóvenes de familias populares «presentes» como las propias.

En paralelo a las valoraciones positivas otorgadas a la actividad, los jóvenes y sus familias mostraron una distancia crítica con las letras de los proyectos y con lo que circula sobre los mismos en distintos espacios sociales. En primer lugar, criticaron con enojo - pero también con ironía - los discursos mediáticos sobre los potenciales beneficios de las orquestas juveniles, en tanto los consideraron exagerados, poco realistas y plagados de prejuicios sobre los jóvenes de barrios populares. En un acto de resistencia a los discursos que los victimizan, no se consideran jóvenes «en riesgo social», ni «vulnerables». Asimismo, a la vez que afirman que en sus barrios «hay transas y mulos, como en todos los barrios», resaltan que la mayoría de habitantes de villas y barrios populares son familias trabajadoras que se esfuerzan por tener «su casa, sus cosas». Para los jóvenes de ambas orquestas es imposible «ganarle a la pobreza con la música» (Clarín, 2005b) o crear «Esperanzas en Barrio Andrade» ${ }^{13}$ (Clarín, 2005a) a partir de un proyecto como el que asisten. Si bien por razones de espacio dejaremos de lado aquí el análisis de las estrategias de identificación que

13 Se ha modificado el título original de la nota para preservar el anonimato y la confidencialidad de los datos. 
despliegan los jóvenes y el lugar que ocupa la orquesta en la construcción de las mismas, es necesario resaltar que los jóvenes comprenden y denuncian que este tipo de interpretaciones están construidas sobre estereotipos estigmatizantes mediante los cuales «es como que dicen ‘mirá los negritos lo que están haciendo». ${ }^{14}$

En segundo lugar, los jóvenes de ambas orquestas se distanciaron de lo que han escuchado decir a muchos de los gestores de los proyectos en los que participan, pues estos discursos apuntan, según los jóvenes, a cuestiones que para ellos no se desprenden de la participación en los proyectos (incremento de la solidaridad, mejora del rendimiento escolar, desarrollo cognitivo o emocional, entre otras). Así, los jóvenes valoran los proyectos pero no por las mismas razones que suponen muchos de quienes los gestionan.

Lo expuesto hasta aquí apareció en ambas orquestas, no obstante, quisiera señalar aquí una de las diferencias más importantes que surgieron en cuanto a la apropiación de cada uno de los proyectos: me refiero a la percepción de impacto entre los participantes. ${ }^{15}$

En la Orquesta A, los jóvenes repetían que participar del proyecto les permitía, en primer lugar, mostrar o demostrar: que, a contrapelo de lo que habitualmente se dice de ellos (jóvenes habitantes de una villa), son capaces de participar de un proyecto que demanda esfuerzo y compromiso, que se distancian tanto de los jóvenes «de la calle» como de los hijos de familias que no trabajan, no terminan sus estudios e incluso de aquellos que viven de la asistencia social. Participar de la orquesta les permite mostrar que ellos no son aquello que la mayor parte de la sociedad argentina cree que son: haraganes o hijos de haraganes, jóvenes «perdidos», sin futuro o, adoptando un calificativo de la programática social, «jóvenes en riesgo».

En la Orquesta B, por su parte, el principal impacto del proyecto se percibía diferente: los jóvenes coincidían en que participar del mismo había sembrado en ellos la idea de descubrir una vocación y de llevar adelante una trayectoria laboral vinculada a ella - aunque no necesariamente en la música.

Para los jóvenes de la orquesta $B$ esta búsqueda de «vivir haciendo algo que te gusta» era producto del intercambio con los docentes y otras personas que habían logrado conocer a través del proyecto, pues

14 Cita de entrevista con participante mujer, 16 años, orquesta B.

15 Si bien surgieron variadas diferencias en este sentido, por razones de espacio me centraré aquí en la que consideré más significativa. 
afirmaban no era un concepto habitual en sus barrios ni en la mayoría de sus familias.

Salvada esta cuestión, que presenta diferencias según cada uno de los barrios, presentaré una tipología con el fin de organizar las similitudes y diferencias en los modos en que cada uno de los proyectos es apropiado por los jóvenes. La misma está basada en el análisis del lugar que ocupan la música y la orquesta en las biografías presentes de los jóvenes, y en lo que imaginan sobre sus proyectos futuros.

i) Tipo 1: los profesionalizados (En vías de... )

Conforman este tipo aquellos jóvenes que han tomado la decisión de hacer una carrera profesional en el ámbito de la música. Estos jóvenes no solo han incorporado un instrumento de manera firme en su proyecto biográfico sino que han comenzado estudios vinculados a la música (universitarios o el conservatorio), se han insertado en formaciones instrumentales (sean estas orquestas sinfónicas, grupos de cámara, formaciones que tocan otros géneros musicales) y/o han conseguido al menos un trabajo en el ámbito musical (docencia, formar parte de una orquesta o grupo de música que permita una entrada de dinero, no necesariamente regular ni muy alta). Incluye a todos los que están llevando adelante una carrera en la música y a quienes al momento del trabajo de campo cursaban estudios secundarios pero estaban convencidos de que ese sería su futuro ( $\mathrm{y}$ forman parte de alguna agrupación musical externa al proyecto).

\section{ii) Tipo 2: una doble vocación}

Son parte de este tipo aquellos jóvenes que han incorporado un instrumento en su biografía pero están haciendo o dicen que harán en el futuro una carrera paralela en otra disciplina. La música y el instrumento son muy importantes para este tipo, dicen que han descubierto parte de su vocación en la orquesta y que el instrumento los acompañará el resto de sus vidas. Algunos estudian música afuera de la orquesta (no carreras universitarias), tocan en ensambles o grupos de cámara, otros nada de eso; pero en este tipo ninguno se imagina que su vida transcurra solo en el ámbito musical. Algunos ponen al mismo nivel la música con la otra carrera o vocación que están llevando a cabo (o que querrían hacer), otros la ponen en segundo lugar; pero no están profesionalizados en la música o solo en ella. 
iii) Tipo 3: la orquesta como un saber, «otra cultura»

Forman parte de este tipo los jóvenes que consideran que la práctica orquestal y el tocar un instrumento implican un saber más entre otros que les gusta o les gustaría tener, un conocimiento que les despierta interés. Para estos jóvenes la posibilidad de hacer música y tocar un instrumento es valorada en tanto implica descubrir «algo nuevo», «desafiante», que a la vez les reporta cierto gusto o goce. Además, valoran lo que aprenden por ser «otra cultura»; es decir, una práctica diferente de las que habitualmente suceden en sus ámbitos cotidianos de socialización. Sin embargo sus trabajos presentes y/o proyectos laborales futuros no están vinculados a la música.

iv) Tipo 4: la orquesta como entretenimiento, diversión

Este tipo hace foco en lo lúdico del proyecto, y no en el tipo de conocimiento que se adquiere en la orquesta. Pone el acento en lo entretenido y lo placentero. Para estos jóvenes la orquesta es diversión, pasatiempo, recreación. Tocar un instrumento y hacerlo en conjunto les reporta un sentimiento de bienestar, además de inaugurar un espacio para «hacer algo». Para estos jóvenes, al igual que para el tipo anterior ni sus trabajos/estudios presentes, ni sus aspiraciones futuras pasaban por el ámbito musical.

TABLA 1: LA DISTRIBUCIÓN DE LOS TIPOS ENTRE LAS DOS ORQUESTAS

\begin{tabular}{|l|c|c|c|c|c|}
\hline & $\begin{array}{c}\text { Los } \\
\text { profesio- } \\
\text { nalizados }\end{array}$ & $\begin{array}{c}\text { Doble } \\
\text { vocación }\end{array}$ & $\begin{array}{c}\text { Un saber, } \\
\text { «otra } \\
\text { cultura» }\end{array}$ & $\begin{array}{c}\text { Entreteni- } \\
\text { miento, } \\
\text { diversión }\end{array}$ & Total \\
\hline Orquesta A & - & 2 & 4 & 5 & 11 \\
\hline Orquesta B & 5 & 4 & 1 & 1 & 11 \\
\hline
\end{tabular}

Como surge de esta tabla, la profesionalización se ha dado solo entre los jóvenes de la Orquesta B; la doble vocación se dio principalmente en la Orquesta B pero también entre algunos jóvenes de la Orquesta A y los tipos 3 y 4: «un saber, otra cultura» y «entretenimiento, diversión» se dieron principalmente entre los jóvenes de la Orquesta A.

Si bien no puede decirse que la distribución exhibida aquí representa los modos en que el instrumento y la práctica orquestal se incorporan en las biografías de todos los participantes, la tipología muestra dos cuestiones. En primer lugar, que hay apropiaciones heterogéneas 
de cada uno de los proyectos analizados, apareciendo algunos tipos solo en uno de ellos y otros solo en el otro. En segundo lugar que los jóvenes - y también sus familias - se apropian de los proyectos ampliando, modificando y reformando gran parte de las ideas que en un principio se plantearon los impulsores de los mismos.

Ahora bien, una vez abordados los modos en que los jóvenes y sus familias conciben la actividad ies posible avanzar en la identificación de elementos que podrían estar influyendo en la construcción de las valoraciones y sentidos expuestos hasta aquí? Si bien, como hemos visto, algunos sentidos son más frecuentes en la Orquesta A y otros en la Orquesta B, ¿alcanza con analizar las diferencias en la oferta para extraer concusiones sobre las diferentes apropiaciones?

\section{b) Prácticas culturales legítimas y hegemonía: brave comentario}

Una parte importante de los aspectos más valorados por los participantes y sus padres/madres son las posibilidades de acceso a nuevos conocimientos y prácticas que habitualmente no tienen lugar entre familias de sectores populares y medio-bajos y que vienen, para decirlo de modo sencillo, desde afuera. Asimismo, evalúan como positivo el contacto con personas que vivieron sus experiencias de socialización en espacios diferentes a los propios (en su mayoría de sectores medios o medios altos), y se entusiasman con las posibilidades que el proyecto brindó de conocer lugares a los que no suelen tener acceso los jóvenes de barrios populares $-\mathrm{y}$ de hacerlo desde el escenario.

La apreciación de la práctica orquestal en barrios populares es con demasiada frecuencia interpretada - tal como lo hace la posición crítica presentada más arriba - en términos de legitimismo cultural: los jóvenes se acercan y permanecen en las orquestas porque las mismas les ofrecen un saber legítimo, valorado socialmente, mediante el cual pueden hacerse a imagen y semejanza de quienes han podido mantenerse en posiciones hegemónicas.

Considero que una lectura de este tipo, si bien podría aplicarse a parte de los testimonios expuestos hasta aquí, implica una reducción de la complejidad del objeto de estudio. Pues la misma no tiene en cuenta sentidos y prácticas habituales entre los jóvenes (en particular en barrios populares pero también afuera de ellos) los cuales pueden, si no impedir, al menos dificultar su acercamiento a proyectos de este tipo. Por ejemplo, la práctica orquestal es percibida por muchos jóvenes como «aburrida» $\mathrm{o}$ «de gente mayor», tal como relataron algunos 
entrevistados que les dicen sus amigos. O como ajena a los estereotipos de masculinidad legítimos en ciertos escenarios barriales, como relataron algunos varones de la Orquesta B: «por tocar flauta traversa algunos me dicen travesaño o travieso»; ${ }^{16}$ «a veces me joden con viola, violín». ${ }^{17}$

Estos ejemplos muestran que es intrincada la apropiación de una práctica que, como la orquestal, los jóvenes de sectores populares viven como ajena. Para complejizar y enriquecer argumentos de este tipo, y para abrir nuevas preguntas que permitan comprender algunos por qué sobre los proyectos de orquestas juveniles y sus diversas apropiaciones, en el próximo apartado se trabajará sobre las trayectorias de las familias de los jóvenes que participan y permanecen en estos proyectos.

\section{c) Pre-requisitos de subjetividad y familiares}

Con la pregunta sobre la identificación de elementos que podrían estar influyendo en los sentidos que adquiere la experiencia orquestal para cada uno de los participantes, se analizaron diversas características de las familias de los jóvenes: datos de posición socioeconómica (educación, trabajo, vivienda), principales trayectorias (laborales, residenciales, migratorias, familiares) y ciertos aspectos culturales - básicamente las adscripciones morales a las cuales manifestaban adherir padres e hijos-. Pues los primeros resultados de mi investigación confirmaban uno de sus supuestos iniciales: que las posibilidades de influencia de un proyecto de educación artística entre sus participantes no dependían solo de lo que los programas ofrecían, sino que adquiría un lugar fundamental aquello que los jóvenes traían consigo como resultado de procesos de socialización previos, todo lo cual constituía una suerte de filtro o tamiz a través y a partir del cual los programas de orquestas podían ser apropiados.

La idea de que existen mediaciones entre el programa y sus «efectos» no es para nada revolucionaria. Sin embargo, en ámbitos técnicos se las suele olvidar cuando se diseñan las intervenciones, $y$, en ámbitos académicos, la mayor parte de los estudios o no las tienen en cuenta o simplemente las enuncian sin avanzar hacia un análisis

16 Eufemismos que asocian la flauta traversa con la travesti o transexual.

17 Eufemismos que asocian el violín con un violador, es decir, con una masculinidad desviada. 
empírico de las mismas. En este apartado me propongo entonces reconstruir algunas de las mediaciones que permiten que las orquestas sean apropiadas por estos jóvenes y estas familias.

El análisis de las trayectorias laborales, educativas, residenciales y familiares relatadas por madres y padres de ambas orquestas resultó heterogéneo. No obstante, surgieron algunas características que compartían prácticamente todas las familias entrevistadas. En primer lugar, todas contaban con al menos uno de sus integrantes (mayormente el padre, aunque en algunos casos la madre o algún hermano mayor) empleado en condiciones formales; algunos de ellos manteniendo sus empleos por diez o quince años. Vale aclarar aquí que en la Argentina esta situación es excepcional entre familias de barrios populares o medio-bajos. En ellos solo el 15\% de los jefes/as de hogar poseían empleos plenos de derechos ${ }^{18}$ al momento del trabajo de campo (BDSA, 2011). Así, la condición laboral coloca a las familias de los jóvenes de ambas orquestas en un lugar diferencial del de la mayoría de sus vecinos, vinculados al mundo del trabajo informal o inestable, de la asistencia, el desempleo o combinaciones de estas cuatro variantes. ${ }^{19}$

En segundo lugar, las familias de los jóvenes de ambas orquestas compartían un conjunto de posicionamientos que referían a criterios de orientación moral, expresados en valores como la perseverancia, el esfuerzo, la responsabilidad, la honestidad y el sacrificio. Estos valores no eran solo pregonados de manera retórica sino que muchas de sus acciones parecían orientadas por ellos. Las referencias a dichas orientaciones valorativas aparecían en sus relatos sobre trayectorias residenciales, laborales, afectivo-familiares y en aquello que demandaban de sus hijos, como ser la finalización de sus estudios secundarios, la consecución de estudios terciarios/universitarios o la búsqueda

18 Por empleos plenos de derechos el Observatorio de la Deuda Social Argentina entiende a los empleados formales o a los cuentapropistas que realizan aportes jubilatorios. (BDSA, 2011).

19 Es importante mencionar aquí que esta situación laboral no tiene implicancias unívocas. Muchas veces dentro de un mismo hogar confluían ingresos provenientes de trabajos formales con otros provenientes de planes o subsidios estatales. O había casos de hogares de 7 a 9 integrantes que contaban sólo con un salario, por lo tanto, por más formal que fueran los ingresos resultarían insuficientes. No obstante, la condición asalariada de la mayoría de las familias implicaba cierta protección social (fundamentalmente salud, jubilación, seguros y pensiones) y cierta disponibilidad de dinero asegurada. 
de un trabajo - en lo posible formal. Como consecuencia de su socialización en estos repertorios morales, casi la totalidad de jóvenes que participaron del estudio en ambas orquestas desafiaban las trayectorias típicas que los estudios sociológicos describen como prevalentes en jóvenes de sectores empobrecidos y populares en la Argentina actual (Kessler, Svampa y González Bombal, 2010; Svampa, 2005; Van Zanten, 2008; Merklen, 2010; Noel, 2009; Reguillo Cruz, 2008; Urresti, 2008 y 2007; Salvia y Chávez Molina, 2007; Kessler, 2000). En lugar de abandonar el secundario lo terminaban (más de la mitad sin repetir ningún año), en lugar de tener hijos a edades tempranas retrasaban los proyectos de maternidad o paternidad con el objetivo de conseguir un trabajo o iniciar lo que consideraban podía derivar en una carrera laboral. Muchos incluso iniciaban estudios terciarios o universitarios.

Ahora bien, ¿qué nos dicen estos hallazgos?

En primer lugar, pareciera que en ambas orquestas convergen cierto tipo de familias de barrios populares y no otras. Familias que, a diferencia de lo que plantean diversos estudios sociológicos recientes en poblaciones empobrecidas o de bajos recursos en la Argentina (Kessler et al., 2010; Svampa, 2005; Salvia y Chavez Molina, 2007), parecieran aún orientar sus estrategias de reproducción en base a valores meritocráticos (perseverancia, esfuerzo, responsabilidad, honestidad, sacrificio). Estos valores solían guiar las prácticas educativas y laborales de las clases medias y trabajadoras argentinas durante el siglo XX (Gutiérrez y Romero, 1995). Pero, según la sociología reciente, la meritocracia ha prácticamente desaparecido en los sectores populares y medio bajos, como consecuencia de los profundos cambios estructurales que generaron procesos de fragmentación y exclusión social. Las nuevas estrategias de reproducción de los sectores populares se basan más bien en una lógica que privilegia lo inmediato y lo posible frente a lo que lleva tiempo y no es seguro de poder conseguir (por ejemplo un diploma de escuela secundaria o un empleo formal), y el corto plazo frente a la planificación (Merklen, 2010; Van Zanten, 2008; Urresti, 2007; Kessler, 2000). 
El dato sobre los repertorios morales ${ }^{20}$ de las familias de los jóvenes participantes de las dos orquestas analizadas debe leerse en conjunto con otros derivados del tipo de propuesta que ofrecen las orquestas. En primer lugar, ambas iniciativas implican constancia, alta frecuencia semanal de clases y ensayos (entre dos y tres veces a la semana), interfieren horarios que pueden alterar las rutinas familiares (ambas orquestas funcionan en horario vespertino y una de ellas además los sábados), suponen la disponibilidad de los participantes para asistir a conciertos fuera de los horarios habituales de encuentro y, en el caso de la Orquesta B, requiere resolver el traslado de los niños pequeños hacia y desde la escuela donde funciona (el proyecto no provee transporte y la escuela no queda igual de cerca para todos). Todo lo cual supone una intensa demanda a las familias de los participantes, quienes se encuentran ya exigidas por la superposición de tareas y actividades de producción material y reproducción familiar.

En segundo lugar, debe tenerse en cuenta que las orquestas también suponen y promueven orientaciones valorativas. Me permito citar aquí las palabras de un docente, pues su claridad excede la de cualquier posible paráfrasis:

La orquesta es como una pequeña sociedad. Cada uno tiene que aprender a cumplir un rol, tienen que escucharse entre ellos, escuchar al director, y todos tienen que caminar juntos... En una orquesta estás ocupando un espacio, si aprendiste y estudiaste vas progresando, en vez de estar en el último atril vas a estar en el primero... Estudiar música implica acumular conocimiento, poner monedas en una alcancía... Es una habilidad acumulativa que empieza a fomentar algunos valores: la perseverancia, la voluntad de sentarse a hacer algo con continuidad durante mucho tiempo. Son una serie de valores que en los chicos jóvenes, no solo acá sino en el mundo en general, se están destituyendo... Hay que comprar hoy y mañana tirar. Estudiar no vale la pena, hay que copiarse: el piola es el ligero que zafa de todo. Nosotros, casi sin darnos cuenta, estamos fomentando otros valores (Docente Orquesta B).

Es sencillo observar que los valores que según este docente son promovidos por el proyecto orquestal se corresponden con aquellos identifica-

20 Retomo el concepto de repertorios morales del Noel (2013), quien los define como las orientaciones valorativas imputables a algún colectivo — del que el sujeto reclama adhesión- y que configuran grados de obligación y deseabilidad relativa de un curso de acción comparado con otros cursos posibles. 
dos en los discursos de los padres de los jóvenes como aquellos que guían sus acciones y decisiones, así como la educación de sus hijos.

Por lo expuesto hasta aquí, pareciera existir una afinidad electiva (Weber, 2007) entre los valores y prácticas promovidas por los proyectos, y los repertorios culturales y morales en los que han sido socializados los jóvenes. Así, la permanencia de los jóvenes en las orquestas estaría dependiendo no solo del gusto por aquello que los programas les ofrecen sino, fundamentalmente, de que ellos y sus familias compartan con la programática social ciertos rasgos culturales y morales que les permitan valorar y priorizar los espacios que ofrecen estos proyectos. Pues, si las familias no priorizaran la actividad de las orquestas, no podrían responder a las exigentes demandas que implican los proyectos para ellas. Asimismo, si los niños y jóvenes que se inician en las orquestas no priorizan el esfuerzo, el sacrificio y el largo plazo, tampoco podrían permanecer en un proyecto que requiere estas competencias de manera permanente. En Argentina, por lo que se ha dicho, no es evidente que una familia en condiciones de vulnerabilidad social priorice una actividad de este tipo para sus hijos - la cual no es asociada a una «salida laboral»-.

Ahora bien, cuando esto ocurre, cuando se alinean algunos de los repertorios culturales y morales entre las familias, los jóvenes participantes y los proyectos, es posible que aparezcan resultados poco frecuentes en barrios populares: jóvenes que se profesionalizan en la música académica, que eligen estudiar en la universidad o en escuelas terciarias, ${ }^{21}$ que adoptan la idea de vocación o carrera profesional como guía para pensar su futuro, que se sienten orgullosos de lo que han logrado, que confían en sus capacidades y creen que podrán trazar trayectorias de ascenso social, que se apasionan con la música académica y sus instrumentos, que encuentran en las orquestas un espacio de socialización fundamental y distinto de los que se ofrecen en sus barrios, que disfrutan de tocar frente a distintos públicos, que se sienten valorados (incluso por personas de otros sectores sociales que habitualmente los estigmatizan), que circulan y conocen distintas zonas de una ciudad cosmopolita a la que la mayor parte de sus vecinos

21 En Argentina el porcentaje de jefes/as de hogar de barrios populares (urbanizaciones informales + urbanizaciones formales de nivel socioeconómico bajo) que terminan el secundario es del 22\% (BDSA, 2011) y el porcentaje que ingresa a la universidad es ínfimo). 
no accede, ${ }^{22}$ y que arman un proyecto biográfico muy diferente al que, según ellos, hubieran armado de no haber mediado estos proyectos.

Ahora bien, ¿podemos avanzar algo más en la comprensión de los modos en que los proyectos orquestales son (o no) apropiados?

\section{d) Gestores, «destinatarios» y la contingencia de la implementación}

Hemos dicho unos párrafos atrás que toda política o intervención se imbrica durante su implementación con una serie de experiencias, trayectorias, saberes prácticos y esquemas de interpretación y significación que traen consigo sus destinatarios. Y que dichas experiencias, saberes prácticos, etcétera. modulan de algún modo aquello que las intervenciones pueden generar entre sus participantes $-\mathrm{y}$, como parecieran sugerir los resultados de esta investigación-, filtran fundamentalmente las posibilidades de permanecer y ser parte de ellas. Asimismo, en el caso de los proyectos analizados, se observa que estos van - de manera progresiva y dependiendo de cada joven- operando sobre dichos esquemas interpretativos, saberes prácticos, etcétera; logrando en algunos casos reformular algunas de sus aristas. Así, las apropiaciones que de la propuesta orquestal realizan los participantes dependen en gran medida de sus trayectorias biográficas y repertorios culturales previos pero también, a partir de su involucramiento con la orquesta, hay posibilidades de que reconstruyan, modifiquen o refuercen parte de dichos repertorios.

En este artículo he reconstruido algunos procesos en donde las orquestas parecieran tener influencia: desde el gusto por la música académica y la intensidad emotiva que para muchos jóvenes implica pararse frente a un auditorio y tocar, hasta los caminos laborales que han iniciado los profesionalizados, pasando por la idea que manifiestan muchos acerca de la música como actividad que los acompañará si no el resto, gran parte de sus vidas. Asimismo, la gran mayoría en ambas orquestas atribuye a su participación en las mismas una apertura de horizontes (acercamiento a nuevos espacios y a formas de pensar y hacer diferentes a las que imperan en sus ámbitos cotidianos de socialización) y, en el caso de la Orquesta B, también asocian a la actividad la idea de vocación o de carrera laboral, aunque no necesariamente en la música.

22 En Buenos Aires las personas que viven en villas o barrios periféricos no suelen salir de ellos en sus circulaciones cotidianas - muchos incluso llegan a conocer el centro de la ciudad cuando son jóvenes o adultos-. 
No obstante - a diferencia de la mayoría de los estudios relevados sobre orquestas juveniles - los resultados de esta investigación sugieren una cierta ingenuidad respecto de la posibilidad de pensar que todo niño/a, adolescente o joven puede acercarse y permanecer en proyectos de estas características — en particular de sectores populares, donde la organización hogareña raras veces puede convivir con las demandas y exigencias que hemos visto requieren estos proyectos-.

Por lo expuesto hasta aquí, y retomando lo dicho en apartados anteriores, es posible afirmar que las orquestas no logran lo que logran por los métodos que quienes las llevan adelante creen aplicar sino por la existencia de una afinidad electiva que provoca una retroalimentación entre los valores y prácticas promovidas por los proyectos y los criterios de orientación moral en los que han sido socializados los jóvenes que se acercan y permanecen en ellos. Cuando esto ocurre, es posible que los proyectos se imbriquen en alguna medida en la reconfiguración de formas de percibir y pensar el mundo de quienes participan en ellos. Puesto de modo más específico: en aquellos casos en los cuales los jóvenes y sus familias (o al menos algún miembro de ellas con influencia en el joven participante) compartan con los que ofrecen los programas ciertas maneras de hacer, de pensarse y de pensar a los demás - fundamentalmente criterios de orientación moral— existirán posibilidades de reforzar estas afinidades iniciales a través de una intervención del tipo de las aquí analizadas.

Ahora bien, a pesar de este argumento inicial que de algún modo homogeneizaría lo posible, hemos visto que existen diferencias significativas entre lo que ha ocurrido en cada uno de los proyectos, así como situaciones diversas al interior de cada proyecto. Por lo tanto, los procesos de recepción y apropiación de estas intervenciones se demuestran heterogéneos.

No obstante, no cualquier joven puede apropiarse de la actividad orquestal de cualquier manera. Por ejemplo, aquellos que han decidido profesionalizarse en la música están solo en la Orquesta B, y los «pioneros» en pensarlo fueron jóvenes en cuyos hogares había algún miembro que o bien leía, o bien veía cine, o bien escuchaba música, o bien tenía alguna profesión vinculada al conocimiento (docentes), o jóvenes que estimulados por algún conocido se acercaban al mundo de las letras y/o las imágenes. Luego los niños/as y jóvenes que vinieron detrás se encontraron con pares interesados en la música académica y en sus posibilidades de profesionalización, y ello ya implicaba un estímulo para pensarse a si mismos en caminos similares. 
La reconstrucción empírica derivada de la investigación realizada me permite afirmar que las posibles modificaciones en cuestiones identitarias, de la subjetividad o en los proyectos biográficos de los jóvenes participantes de las orquestas son el resultado específico de intersecciones también específicas entre i) los mandatos de una política o intervención artístico-cultural (en este caso lo que ofrece cada proyecto), ii) lo particular que aportan quienes la llevan adelante (docentes y otros gestores), iii) la contingencia del encuentro entre gestores y participantes, en un tiempo y un barrio determinados; y iv) las trayectorias biográficas y repertorios culturales que ponen en juego los beneficiarios. Estas dimensiones no son estáticas sino procesos dinámicos que a la vez se influencian mutuamente, y que ocurren en el marco de procesos estructurales también cambiantes que van configurando, entre otras cosas, los modos de pensar la acción cultural y la política social en nuestro país y en diversas latitudes del mundo occidental.

\section{INCLUSIÓN VERSUS DOMINACIÓN: RESABIOS DE UNA DISCUSIÓN DESVENCIJADA}

Al comienzo de este artículo me posicioné a distancia de las interpretaciones que celebran o critican las intervenciones culturales con «fines sociales» fundamentalmente porque, en contraste con lo que se ha intentado realizar aquí, las mismas implican generalizaciones derivadas de razonamientos deductivos que no contemplan la heterogeneidad de posiciones y situaciones sociales desde las que es posible aprehender una práctica como la orquestal en sectores populares. Estas interpretaciones tampoco le dan el lugar que merece a las tensiones de diversa índole que aparecen durante los procesos de implementación de este tipo de proyectos - de los cuales tampoco hemos podido dar cuenta aquí más que indiciariamente-.

Quisiera introducir algunos comentarios adicionales. En primer lugar, recalcar - aunque entiendo se desprende de los resultados presentados - que el enfoque aquí propuesto no desconoce que las artes son prácticas sociales situadas, atravesadas por relaciones de poder, y está lejos de otorgar a la música sinfónica un estatus superior al de otros géneros o prácticas musicales. Tampoco desconoce que la música académica y la práctica orquestal forman parte del repertorio de bienes culturales legítimos y que su extensión a sectores de la población habitualmente alejados de ellos conlleva una serie ineludible de preguntas sobre por qué lo que se democratiza son este tipo de prácti- 
cas y no otras, por qué se asume que la música culta es moralmente superior a otros géneros o estilos musicales, por qué se resuelve de manera unilateral qué práctica artística se va a ofrecer a poblaciones que podrían participar en esta decisión, y si todas estas cuestiones no implican que las orquestas juveniles forman parte de los modos de dominación de los sectores subalternos.

Concuerdo con las posiciones críticas en que, por todas estas razones, no podemos sobreestimar la potencialidad transformadora de las artes. Ahora bien, interrogándonos en sentido opuesto, ¿es posible afirmar que el hecho de apropiarse de parte del repertorio legítimo de bienes culturales implica un acto de subordinación? Las referencias de los jóvenes al disfrute y al placer de tocar un instrumento y hacer música en conjunto ¿pueden solo ser interpretadas en términos de hegemonía cultural? Si, como hace años nos alertara Michel de Certeau (1996:XLI) los usuarios no están «condenados a la pasividad y a la disciplina» sino que tienen sus propios esquemas de acción aún cuando están en condición y posición dominada, si como afirma Alabarces (2008), las culturas populares nos hablan hoy más de negociaciones e intercambios que de resistencias puras; si los procesos de mundialización y transnacionalización generan que la correspondencia entre clase social y bienes culturales no resulte transparente sino que primen las trasposiciones, los flujos transversales, las apropiaciones y reapropiaciones entre la alta cultura y las culturas populares aún en el marco de relaciones de hegemonía/subalternidad (Alabarces, 2011); si los consumos, posesiones y prácticas de la cultura popular son siempre ambivalentes y contradictorios (Grignon y Passeron, 1991); y si el principio de escisión gramsciano implica más una «posición diferencial de los subalternos que les permite pensarse, aún en las situaciones de hegemonía más impenetrables, como distantes y diferentes de las clases dominantes» (Alabarces, 2008:25) —cuestión que el estudio realizado ha evidenciado en diversas oportunidades-. Entonces iresulta fructífero el par dominación/resistencia para interpretar programas y proyectos como los aquí analizados?

El planteo de George Yúdice (2002) sobre la cultura como recurso para mejorar cuestiones sociales y económicas también va en esta línea. El hecho de que la cultura sea utilizada para alcanzar fines implica una nueva episteme, de características posmodernas, que favorece la performatividad —entendida como la competencia de muchos y diferentes principios de inclusión y exclusión, y no de leyes fundamentales-. Así, las sociedades y las personas son campos de fuerza 
donde prima la multiplicidad - aunque dentro de contornos sociales definidos - y, por lo tanto, existen distintas recepciones del trabajo cultural que están condicionadas por las expectativas que tienen las personas o grupos, que a su vez responden a distintos entramados o campos de fuerzas performativos. No obstante estas multiplicidades, vale la pena retomar el concepto de circularidad de Mijail Bajtín (1987) para alertar sobre la existencia de posiciones disimétricas entre culturas letradas y culturas o sectores populares. Si bien existe un movimiento de intercambio y circularidad entre lo popular y lo letrado, ese intercambio no se realiza en términos de igualdad.

Lo particular de los proyectos de «democratización del arte» ${ }^{23}$ es que combinan dos grupos de discusiones sobre el poder: aquellas derivadas del componente cultural (es decir, por qué son determinadas prácticas las que se extienden a determinadas poblaciones), y aquellas derivadas del componente social, las cuales involucran tanto cuestiones político-filosóficas (qué tipo de sociedad se busca, cuáles son las mejores maneras de llegar a ella, quiénes son los encargados de pensar estas maneras, etcétera) como ético-morales (la dignidad de las personas bajo asistencia, las relaciones entre grupos sociales divergentes y con acumulaciones desiguales de capitales, etcétera).

El hecho de afirmar que existe una distancia crítica por parte de los jóvenes y sus familias no implica ignorar las condiciones estructurales que rodean y limitan las decisiones y agencia de los participantes - de hecho los límites que presentan los programas analizados en términos de permanencia de niños/as y jóvenes de sectores populares marginalizados - ha sido parte central del argumento de este trabajo. La implicancia de los resultados presentados aquí es que las constricciones existen pero no siempre tienen el sentido y la dirección que los analistas solemos imaginar a priori. Asimismo, no es sencillo reconocer en ellos «lo dominante, lo asociado y lo subordinado» (Williams, 2000:178).

23 La democratización cultural es uno de los paradigmas políticos de la acción cultural en América latina según García Canclini. El mismo «concibe la política cultural como un programa de distribución y popularización... de las formas de la alta cultura» (García Canclini, 1987:46) basado en la hipótesis de que una mejor difusión de las mismas implicará una disminución de las desigualdades en el acceso a los bienes simbólicos. 
Una mirada atenta a los procesos complejos que se evidencian en este tipo de proyectos no puede más que desestimar la celebración integradora y la crítica centrada en la dominación del pueblo en tanto posiciones vetustas. Y apelar a una mirada que se centre las ambivalencias, tensiones y ambigüedades que tienen lugar en estas intervenciones, las cuales involucran a cada paso cuestiones de legitimidad, poder y dignidad que los participantes y sus familias casi nunca están dispuestos a negociar.

Buenos Aires (ARGENTINA), ENERO/ABRIL 2015

RECIBIDO: ABRIL 2015

ACEPTADO: SEPTIEMBRE 2015

\section{REFERENCIAS BIBLIOGRÁFICAS}

ApPle, Michael (1996): Política cultural y educación. Madrid: Morata.

ALABARCES, PABLO (2011): «Las culturas populares: cuánto queda de resistencia y cuánto falta de poder». En AMEIGEIRAS y ALEM (comp.): Culturas populares y culturas masivas. Los desafios actuales a la comunicación. Buenos Aires: Imago Mund-UNGS.

(2008): «Introducción. Un itinerario y algunas apuestas» en ALABARCES y RODRÍGUEZ (comp.): Resistencias y mediaciones. Estudios sobre cultura popular. Buenos Aires: Paidós.

Álvarez LEGUIZAMÓN, SONIA (2006): «La invención del desarrollo social en la Argentina: historia de 'opciones preferenciales por los pobres'. En ANDRENACCI (comp.): Problemas de política social en la Argentina contemporánea. Buenos Aires: Paidós y Universidad Nacional de General Sarmiento.

(2005): «Los discursos minimistas sobre las necesidades básicas y los umbrales de ciudadanía como reproductores de la pobreza». En SONIA ÁlVAREZ LEGUIZAMÓN (comp.): Trabajo y producción de la pobreza en Latinoamérica y El Caribe: estructuras, discursos y actores. Buenos Aires: CLACSO. Disponible en: http://bibliotecavirtual.clacso.org.ar.

ATEla, MARÍA VALERIA (2005): «Orquesta-Escuela como herramienta educativa y de promoción sociocultural: descripción de una experiencia y aspectos de una investigación en curso». Ponencia presentada en las Jornadas de Educación Artística de la Escuela de Posgrado de la Facultad de Humanidades y Arte, Universidad Nacional de Rosario, octubre de 2005.

BAJTín, MijaIL (1987): La cultura popular en la edad media y en el renacimiento. Madrid: Alianza Editorial. 
BARÓMETRO DE LA DEUDA SOCIAL ARGENTINA (2011): Estado de situación del desarrollo humano y social. Barreras estructurales y dualidades de la sociedad argentina en el primer año del Bicentenario (Serie del Bicentenario 2010-2016, Año 1). Buenos Aires: Universidad Católica Argentina. Disponible en: http://bibliotecadigital.uca.edu.ar.

CHAVES, MARIANA (2005): «Juventud negada y negativizada: representaciones y formaciones discursivas vigentes en la Argentina contemporánea». Última Década N²3. Valparaíso: Ediciones CIDPA.

Chavitarese de SouZA LiMA, MARÍA José (2007): «O canto coral como agente de transformação sociocultural nas comunidades do cantagalo e pavão-pavãozinho: educação para liberdade e eutonomia». Río de Janeiro, RJ. Tesis de Doctorado en Psicosociología de Comunidades y Ecología Social, Universidade Federal do Rio de Janeiro, Instituto de Psicología.

CLARÍN (2005a): «Esperanzas en Villa Lugano». Sección Espectáculos publicado el 3 de marzo de 2005. Buenos Aires: Clarín.

(2005b): «Los chicos que le ganan a la pobreza con su música». Sección Ciudad publicado el 4 de septiembre de 2005. Buenos Aires: Clarín.

CRítica DE LA ARGENTINA (2008): «Y la banda sigue tocando». Buenos Aires. 29/9/2008.

De Certeau, Michel (2000) [1990]: La invención de lo cotidiano 1. Artes de hacer. México DF: Universidad Iberoamericana.

De Couve, Alicia, Claudia dal Pino (2007): «Las orquestas infantiles y juveniles: el proyecto venezolano y la propuesta del Gobierno de la Ciudad Autónoma de Buenos Aires (ZAP) ¿una réplica?». Trabajo presentado en el 2do. Congreso Nacional y 1er Encuentro Latinoamericano de Estudios Comparados en Educación. SAECE, Buenos Aires, 14 al 16 de Julio. Disponible en: www.saece.org.ar.

Del Cueto, Carla MurIEL (2006): «Desde el barrio. Un estudio sobre acción cultural en dos barrios del Gran Buenos Aires». Cuadernos de CLASPO-Argentina $\mathrm{N}^{\circ}$ 3. Buenos Aires: CLASPO-Argentina.

EGAÑA DEL SOL, PABLO (2007): «Orquestas infantiles y juveniles: evaluación de impacto en rendimiento escolar». Encuentro Anual de la Sociedad de Economía de Chile, Reñaca, 2007. Disponible en: www.sechi.cl.

FERNÁNDEZ CALVO, DiANA (2003): «La integración social de los niños y jóvenes pobres, a través de la música: proyectos de orquestas juveniles en América Latina y en la Argentina».

Disponible en: www.especialmentemusica.com.ar.

FreIRE, PAUlo (2005): Pedagogía del oprimido. México: Siglo XXI.

GARCÍA CANCLINI, NÉSTOR (1987): «Políticas culturales y crisis de desarrollo: un balance latinoamericano». En GARCÍA CANCLINI (ed.): Políticas culturales en América Latina, México: Grijalbo.

GCBA. GOBIERnO DE LA CIUDAD DE BuENOS AIRES (2009a): «Orquestas juveniles». Disponible: www.buenosaires.gov.ar. 
(2009b): «Orquestas infanto-juveniles»

Disponible: www.buenosaires.gob.ar.

GIROUX, HENRY (1988): «Literacy and the Pedagogy of Voice and Political Empowerment». Educational Theory $\mathrm{N}^{\mathrm{o}} 38$.

Grignon, Claude y JeAn Claude PASSERon (1991) [1989]: Lo culto y lo popular. Miserabilismo y populismo en sociología y en literatura. Buenos Aires: Nueva Visión.

GUBER, Rosana (2001): La etnografía. Método, campo y reflexividad, Buenos Aires: Editorial Norma.

GutiÉRREZ, LEONARdo y LUIS ALBERTO ROMERO (1995): Sectores populares, cultura y política. Buenos Aires: Sudamericana.

HikiJi, Rose SATIKO GITIRANA (2006): «Música para matar o tempo intervalo, suspensão e imersão». Mana, Vol.12, No 1 .

Joly, Ilza Zenjer Leme, Glauber Lúcio Alves, Maria CAROlina LeME Joly, Edison DonizeTti LeITE PENTEAdo (2002): «Formação de orquestras com crianças de classes populares: uma proposta para constituição da cidadania». Anais da Associação Brasileira de Educação Musical Abem, Natal / RN, Vol. 1.

KAPLUM, GABRIEL (2004): «Culturas juveniles y educación: pedagogía crítica, estudios culturales e investigación participativa». En Los jóvenes: múltiples miradas. Neuquén: UNC.

Kessler, Gabriel, Maristella Svampa e InÉs GonzÁlez Bombal (2010): Reconfiguraciones del mundo popular. El conurbano bonaerense en la postconvertibilidad. Buenos Aires: Prometeo-UNGS.

(2000): «Redefinición del mundo social en tiempos de cambio. Una tipología para la experiencia de empobrecimiento». En M. SVAMPA (ed.): Desde abajo. La transformación de las identidades sociales. Buenos Aires: Biblos-Universidad Nacional de General Sarmiento.

Koselleck, ReInHart (1985): Futures Past. On the semantic of Historical Time. Cambridge (Mass.), MIT Press.

LA NACIÓN (2004): «Música para romper el círculo de la pobreza». Sección Espectáculos. Buenos Aires. Publicado el 3 de octubre de 2004

— (2005): «Jóvenes en riesgo social, unidos por la música». Sección Sociedad. Buenos Aires publicado el 31 agosto de 2005

LA NACIÓN REVISTA (2005): «La música de todos». Buenos Aires publicado el 22 mayo de 2005.

LANDI, ÓSCAR (1987) «Campo cultural y democratización en Argentina». En García CANClini (ed.): Políticas culturales en América Latina, México: Grijalbo.

MERKLEN, DENIS (1987) «Campo cultural y democratización en Argentina». En García Canclini (ed.): Políticas culturales en América Latina, México: Grijalbo.

LANDI, ÓSCAR 2010 [2005]: Pobres ciudadanos. Las clases populares en la era democrática argentina (1983-2003). Buenos Aires: Gorla. 
- (1987): «Campo cultural y democratización en Argentina». En GARCÍA CANCLINI (ed.): Políticas culturales en América Latina, México: Grijalbo. NoEL, GABRIEL (2013): «De los códigos a los repertorios. Algunos atavismos persistentes acerca de la cultura y una propuesta de reformulación». Revista Latinoamericana de Metodología de las Ciencias Sociales; Vol.3, $\mathrm{N}^{\circ} 2$.

- (2009): La conflictividad cotidiana en el escenario escolar: una perspectiva etnográfica. Buenos Aires: UNSAM.

REguillo, Rosana (2008): «Instituciones desafiadas. Subjetividades juveniles: territorios en reconfiguración». En E. TENTI FANFANI (ed.): Nuevos temas en la agenda de política educativa, Buenos Aires: Siglo XXI.

REPETTO, FABIÁN y LUCIANO ANDRENACCI (2006) «Ciudadanía y capacidad estatal: dilemas presentes en la reconstitución de la política social argentina». En LUCIANO ANDRENACCI (comp.): Problemas de política social en la Argentina contemporánea. Buenos Aires: Paidós y Universidad Nacional de General Sarmiento.

RUBINICH, LUCAS (1993): Extensionismo y basismo: dos estilos de política cultural. Buenos Aires: Espacio.

Salvia, Agustín y Eduardo Molina Chávez (2007): Sombras de una marginalidad fragmentada. Aproximaciones a la metamorfosis de los sectores populares de la Argentina. Buenos Aires: Miño y Dávila.

SVAMPA, MARISTElla (2005): La sociedad excluyente: la Argentina bajo el signo del neoliberalismo. Buenos Aires: Taurus.

Turner, Graeme (1996): British Cultural Studies. An Introduction. Second Edition. London and New York: Routledge.

UNICEF, SECRETARÍA DE CULTURA DE LA NACIÓN y FUNDACIÓN ARCOR (2008): Arte y ciudadanía. El aporte de los proyectos artístico-culturales a la construcción de ciudadanía de niños, niñas y adolescentes. Buenos Aires: UNICEF, Secretaría de Cultura de la Nación y Fundación Arcor.

URRESTI, MARCELO (2008): «Nuevos procesos culturales, subjetividades adolescentes emergentes y experiencia escolar». En E. TENTI FANFANI (ed.): Nuevos temas en la agenda de política educativa, Buenos Aires: Siglo XXI.

(2007): «De la cultura del aguante a la cultura del reviente: cambios en la significación de la corporalidad en adolescentes y jóvenes de sectores populares». En M. MARGULIS (ed.): Familia, hábitat y sexualidad en Buenos Aires: investigaciones desde la dimensión cultural. Buenos Aires: Biblos.

PNUD (1998): Experiencias exitosas en reducción de la pobreza. Caracas: PNUD.

VAN ZANTEN, AGNes (2008): «¿El fin de la meritocracia? Cambios recientes en las relaciones de la escuela con el sistema económico, político y social». En E. TENTI FANFANI (ed.): Nuevos temas en la agenda de política educativa, Buenos Aires: Siglo XXI. 
Velasco SAN MARTín, PATRicia (2009): «Orquestas juveniles e infantiles de Chile: Una estrategia de inclusión. Estudio de caso sobre las orquestas de Curanilahue». Tesis de maestría en Antropología y Desarrollo. Universidad de Chile, Facultad de Ciencias Sociales, Departamento de Antropología.

WALD, GABRIEL (2012): «La cultura como recurso. Sentidos y apropiaciones de dos programas de orquestas juveniles de la Ciudad de Buenos Aires». Buenos Aires. Tesis de Doctorado en Ciencias Sociales, Facultad de Ciencias Sociales, Universidad de Buenos Aires.

WEBER, MAX (2007) [1904]: La ética protestante. Buenos Aires: Libertador.

WILLIAMS, RYMOND (2000) [1977]: Marxismo y literatura. Barcelona: Península.

WinOCur, Rosalía (1996): De las políticas a los barrios. Programas culturales y participación popular. Buenos Aires: Miño y Dávila.

WOLCOTT, HARRY (2006): «Some Thoughts about Ethnography». Trabajo presentado en el $\mathrm{XI}^{\mathrm{o}}$ Simposio de Investigación Etnográfica en Educación. Buenos Aires, marzo de 2006.

YUdiCE, GEORGE (2002): El recurso de la cultura. Usos de la cultura en la era global. Barcelona: Gedisa. 